\title{
Digital Storytelling Makes Reading Fun and Entertaining
}

\author{
Ariffin Abdul Mutalib \\ International College \\ University of Science and \\ Technology \\ Sana'a Yemen
}

\author{
Nurulnadwan Aziz \\ Faculty of Office Management \\ and Technology \\ Universiti Teknologi MARA \\ Terengganu, Malaysia
}

\author{
Zatul Amilah Shaffiei \\ Faculty of Computer Science \\ and Mathematics \\ Universiti Teknologi MARA, \\ Selangor, Malaysia
}

\begin{abstract}
This paper reports on an ongoing study, which determines whether digital storytelling is fun and entertaining. Since the digital storytelling has attracted research attention, children's experience with regards to fun and entertaining when interacting with it should be studied, because they are the generation to utilize the technology. Hence, this study is carried out. This paper starts with some discussions on the background. It highlights the history of reading materials and their chronology. Also, some previous studies on fun and entertaining are reviewed. Then the activities involved in this study are described, including the development of digital storytelling that adapts the user-centered design approach. Further, a user test of the digital storytelling is elaborated including the results obtained. Next, the results are discussed in relation with the experience, before the conclusion section follows at the end. It was found that digital storytelling is really entertaining and invoking fun.
\end{abstract}

\section{General Terms}

Multimedia, human-computer interaction

\section{Keywords}

Digital storytelling, children, usability, fun, and entertaining

\section{INTRODUCTION}

Reading is very important in gathering information and generating knowledge. It is stressed in the Quran clearly through Surah al-'alaq, urging people to read for the benefits of making improvements. The reading activities involve reading materials, which is associated with books [1]. The books are created in many forms. Overall, books can contain text, pictures, colors, and other elements [2]. In addition, books are created differently for different target users such as children and adults [3]. History has shown the chronology of book forms.

In the old age, information was written on artifacts like stones, and woods. The utilities of these kinds of books were very limited to write and read only. Then the paper was used to write. In the paper books, more reading activities could be utilized such as highlighting, page marking, annotating, sketching, and pasting other stickers. Further, with technologies supports, the books are transformed into digital version and called electronic book (eBook) [2]. There are many definitions of eBook which was started with the efforts in converting paper books to digital form [2] usually through digitization processes which allow them to be displayed on computers. The eBook supports all functions contained in the paper books with additional features such as navigation, page searching, word searching, and audible cue [4]. The benefits of eBooks have been extensively explored by researchers since the 19's such as by [2], [1], and [5]. Later, the locus of eBook types was expended. Recent definition of an eBook has been extended to include book titles that are available online, can be read as email, can be retrieved by a portable electronic reading device, or as a file that can be downloaded onto a computer [2]. Previously, [6] classified an eBook according to three different criteria:

- Portable eBook, which can be taken everywhere and whose main purpose is to reproduce the portability of paper books. These are normally used for referenced publications, dictionaries, and thesauri;

- Books those are more concerned with preserving the logical structure that is the organization of a book in chapters, sections, and subsections. These provide full-text indexing, links, navigation, and orientation through dynamic tables of contents and multi-window text displays;

- Books which support both the logical and physical aspects of a book.

The eBooks can be read either on hardware-based reader and software-based reader [1]. Hardware-based readers are machines produced specifically for reading downloaded electronic contents. They are lightweight devices, with utilities to duplicate the familiar experience of reading the paper book. On the other hand, software based-readers function in a similar way to the hardware-based readers but no special hardware is required. Microsoft Reader, Adobe Acrobat Reader, and Adobe Acrobat eBook Reader are examples of such software [7]. Besides, The International Children Digital Library has developed the software-based reader applications for reading their eBooks [5].

Inline with the eBook implementation worldwide, other learning and reading technologies such as courseware and web sites were taking place. Coursewares are developed for access through the web, or for use on CD. For instance, [8] use courseware in their computer-integrated classroom as the content repositories. Among the advantages of courseware, in which hypertexts are utilized, is the ability for learners to read in different orders. Every page contains links to a number of different pages which can be read next. Basically in courseware, the 'browse and click' is the main interaction approach. Web sites are developed with all features in the courseware, but it is only available in the Internet, and requires the Internet connection to work.

In current age, the reading activities are enriched with a timely approach especially in storytelling which is called digital storytelling (DST). When issues relating to making experience over electronic technologies fun and entertaining are raised [9], [10], and [11] the DST can be tackled in relation with reading activities. If the reading is fun and entertaining, the readers will 
engage deeply into the flow [4], and the content could be enjoyed better [3]. In fact, [12] stated that fun and entertainment are becoming increasingly important in almost all uses of information technology. In addition, [13] address that designers are not only designing products to ensure products work well (functionality - task-focused) and usable (usability - userfocused), but also to go beyond those aspects, so that the products satisfy (satisfactory - experience-focused) the intended users.

Beyond usability is the satisfaction, which no amount of validation testing or quality assurance testing would reveal [14]. The measure could only come from users, using many techniques of data collection [15], [16], [17], [14], [18], and [3]. User satisfaction focuses on how users experience a system, and is classified as experience-focused aspect of a system.

There were few research carried out on measuring satisfaction despite the aspects of ease of use and effectiveness [15]. However, in recent literatures, attempts are found to research in the subject [19], [20], [21], [22], and [23]. Besides, attempt to shift from usability alone to user experience which is analogous to an iceberg [24] is also included in work by [25]. Probably, their works could rationalize the statement by [25], who stated that designing for enjoyment is not as designing for usability. Then, [26] and [10] further explored the satisfaction. Later, the work in investigating user satisfaction was extended by [11]. In addition, experience is closely related to feelings and emotions. Using heuristics may help in recognizing emotions [27]. In relation, works investigating users feeling and emotions can be found in [9], [28], [29], [30], [31], [32], [33], [34], and [35]. Also, they are found in [36], [37], [38], [39], [40], [41], and [42]. Those researches include fun and entertaining as aspects in the experience-focused component.

With regards to the discussions on DST and experience-focused, this paper aims at investigating whether the DST are entertaining and invoking fun among children. This section discusses the history of reading materials and its chronology. Also, previous studies relating fun and entertaining are outlined. Next section describes the activities carried out in this study, which is followed with a section outlining the results. Then, the results are discussed in another section before the final section concludes the paper by addressing the next step of the study.

\section{METHODOLOGY}

This study involves two phases, first the development works of a DST. This part adapts the user-centered design (UCD) approach, in which each artifact is evaluated with the users [43]. UCD refers to a design approach in which the potential users are involved in the designing team, especially in evaluating all artifacts at each designing stage. Second, user test followed. Even though all artifacts at each design stage are evaluated by the users, the finished interactive DST must be evaluated so that users get and experience the actual representation of the developed DST. The activities involved in both phases are outlined in Figure 1.

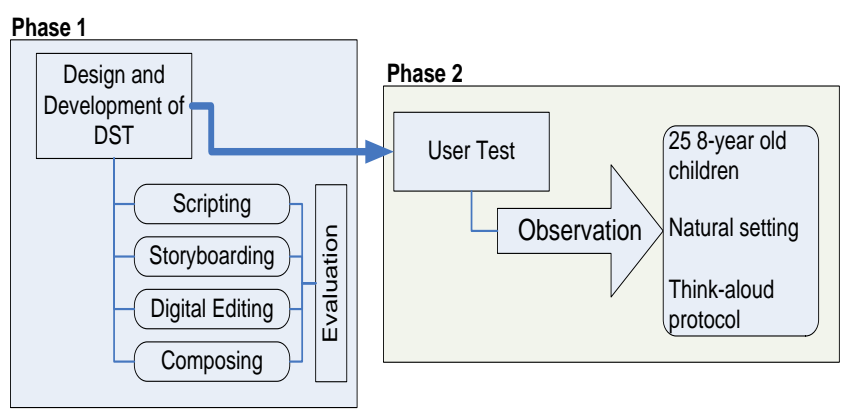

Fig 1: Research methods

Figure 1 explains that the development of DST was begun with script writing. The script is very important to convey the storytelling to the users. After the script has been confirmed and accepted by the users, the storyboarding began. Storyboard represents the storytelling in graphical illustrations. It also represents how the storytelling looks in digital form when fully developed. The storyboard has also been approved by the users. This is to ensure that users are satisfied with the flow design of the DST.

Having confirmed the storyboard, the process proceeded with digital editing. This refers to preparing elements for the DST. The elements include all audio, pictures, text, video, animation, and buttons. Users involved in agreeing upon the elements by analyzing each element in groups. This was a long process. Also, the transition behaviors were analyzed by the users. Finally, the elements were composed into a working prototype. It involved integrating all elements as described in the storyboard. When the DST was ready, it was assessed by the users in a proper user test.

In the user test, 25 8-year old children were involved in natural setting. The 18-year old children were selected for testing after considering that they have normally started to read books, and in the period of developing their reading habit. They were observed closely when interacting with the DST in their normal environment at school. In addition, the children were also interviewed for additional data. The user test was focused at gathering information and feedback on features the users prefer and confused.

\subsection{The Development}

This section presents the DST developed in this study, with design principles incorporated. Tarzan was chosen to suit the children, because it is a famous character among children. The social values in the story include sincerity, caring, love, challenge, and happiness. Figures 2 to 7 depict samples of snapshots of the developed DST. 


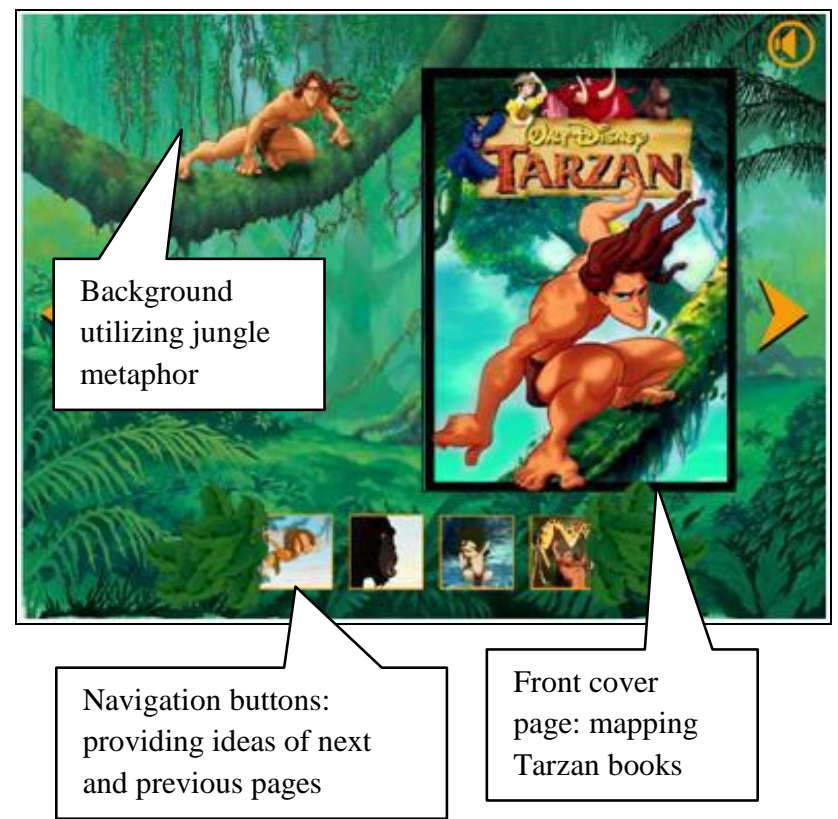

Fig 2: Front page

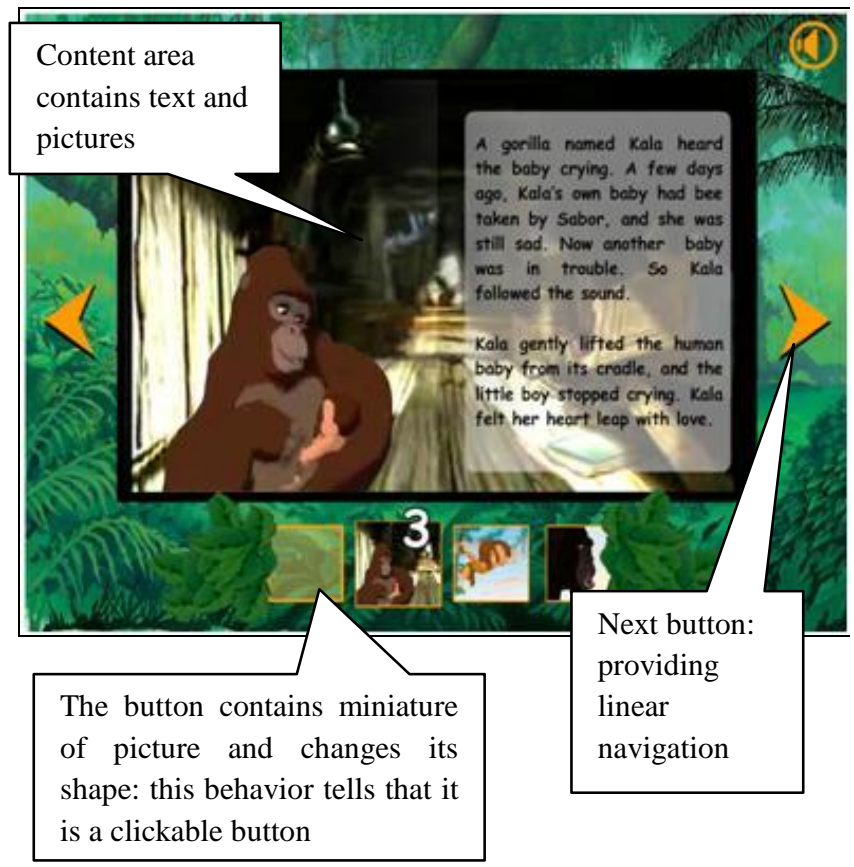

Fig 3: Page contains text and pictures

Figure 2 shows the front cover of the DST. It maps very much with Tarzan books in the market. This is purposely designed to trigger children's cognition, which supports their ability to recognize. The metaphor for the DST background is also representing the habitat of Tarzan, which makes children associate and connects the story with their existing knowledge about Tarzan. Each page is provided with linear and hybrid navigation buttons as can be seen in Figure 3. In addition, all navigation buttons change their shape or color to express that they are clickable. The hybrid navigation buttons are also the miniature of respective page, and also annotates its page number when the mouse rolls over (Figure 3 ). Figure 3 also shows that a page contains at least text and pictures.

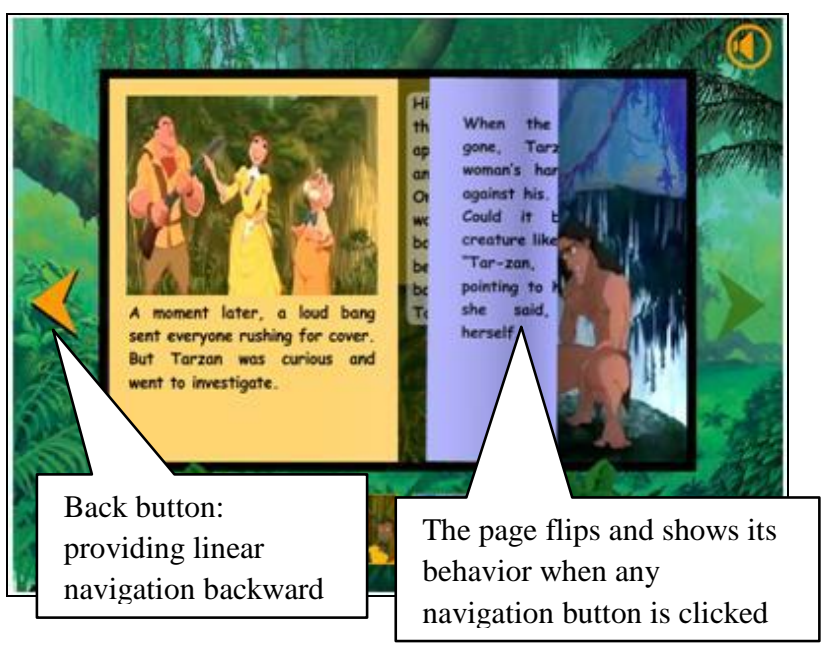

Fig 4: Page flipped forward

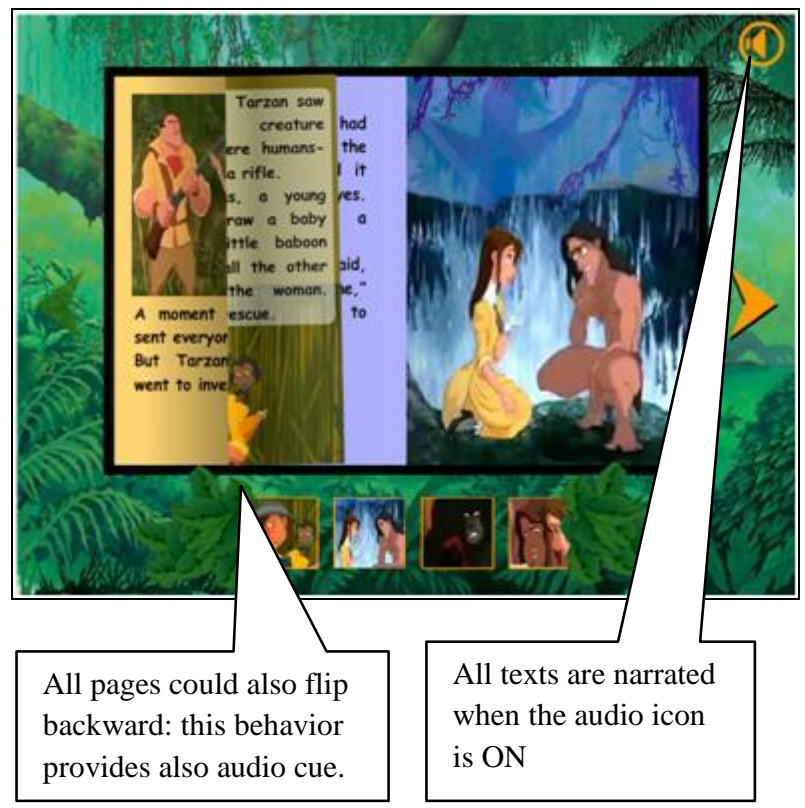

Fig 5: Page flipped backward

The way pages turn is designed well, in which when any navigation button is clicked, the current page will flip. The behavior is seen on screen as depicted in Figure 4. This notifies that the page changes, applying the direct manipulation principle. The pages flip in response to the clicked navigation button; Figure 4 depicts the effects when the next button is clicked, while Figure 5 depicts the effects when the back button is clicked. 


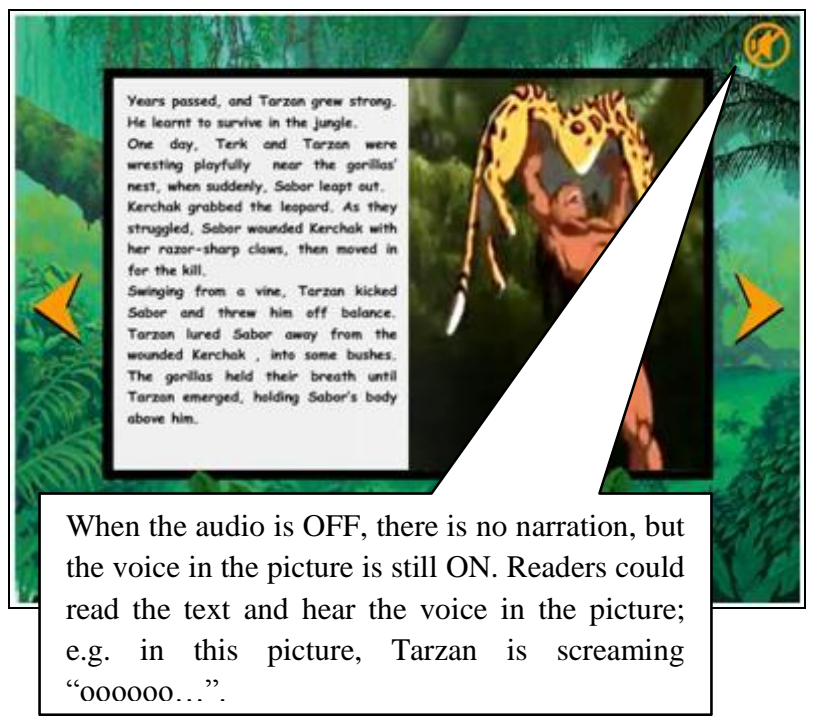

Fig 6: Page with audio OFF

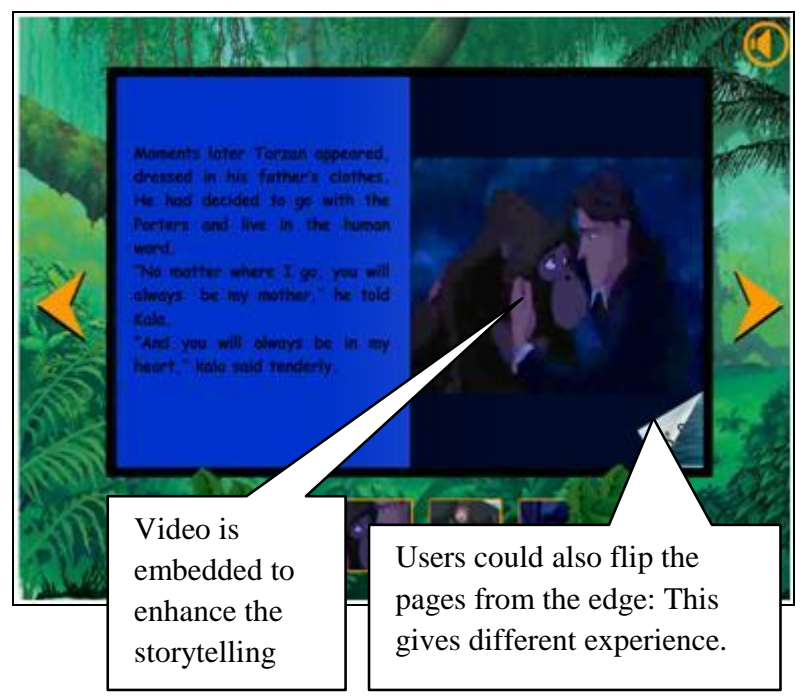

Fig 7: Page with video

All texts on all pages are narrated for the readers. They are narrated with proper emphasis, stress, and intonation, giving the real feel of the story. Dialogs by each character are ensured spoken by a similar narrator to associate the voice with the character from start to finish. However, the narration could be turned OFF by the readers on their choice. It is possible by just clicking the button as depicted in Figure 6 once. This reduces readers' tasks, and provides options to them which avoid the DST from controlling them. Besides text, picture, and audio, the DST incorporates also video to enhance the storytelling. Video element (as seen in Figure 7) really demonstrates the story.

The paragraphs above explain about the DST developed in this study, with relation to some design principles. The DST was designed incorporating design principles for children, to make sure that the test results are strong, and are generalizable.

\section{OBSERVATIONS AND RESULTS}

There were 258 -year old children involved in the observation. They were employed from two primary schools. All children were selected among those who have a computer at home and use computers daily. This is to ensure that they have good computer background, so that their feedback can represent also those who are not used to computers.

Each subject used the DST in their natural setting individually in their school, but their friends were allowed to entertain them. They control the DST and were communicating with their friends while using the DST. Think-aloud protocol was applied, in which the participants were encouraged to speak-aloud all their ideas about the DST while using it [44] to understand their inner feelings. Data were collected by taking notes over participants' comments and body languages.

[13] discuss about the criteria for entertaining and fun, as the basis of developing Q-MEF; an instrument used in measuring perceptions on entertaining and fun quantitatively [45]. Accordingly, the criteria are listed in Table 1. Further the criteria in Table 1 were used in observing the subjects when interacting with the DST.

Table 1. Criteria for entertaining and fun

\begin{tabular}{|c|c|c|c|}
\hline \multicolumn{2}{|c|}{ Entertaining } & \multicolumn{2}{c|}{ Fun } \\
\hline 1 & $\begin{array}{c}\text { Attracting and } \\
\text { capturing attention }\end{array}$ & 1 & Laugh \\
\hline 2 & $\begin{array}{c}\text { Provoking } \\
\text { perceptions }\end{array}$ & 2 & Humor \\
\hline 3 & Arousing emotions & 3 & Relax \\
\hline 4 & Interesting & 4 & Happy \\
\hline 5 & Challenge & 5 & Fun \\
\hline 6 & Appealing & 6 & Enjoyable \\
\hline 7 & Encouraging & 7 & Excited \\
\hline 8 & Entertaining & & \\
\hline 9 & Guiding & & \\
\hline 10 & Engaging & & \\
\hline 11 & Flexible & & \\
\hline
\end{tabular}

\subsection{Result}

Data gathered in this study are in qualitative form. From the observations through the think-aloud protocol and body language, the data as listed in Table 2 have been gathered.

\section{Table 2. Data from Observation}

\begin{tabular}{|c|c|}
\hline Criteria & Description \\
\hline $\begin{array}{c}\text { Entertaining: data gathered through subjects comments on the } \\
\text { features in think-aloud }\end{array}$ \\
\hline $\begin{array}{c}\text { Attracting and capturing } \\
\text { attention }\end{array}$ & $\begin{array}{c}\text { The storytelling, the metaphor, } \\
\text { the buttons, the characters, the } \\
\text { media elements. }\end{array}$ \\
\hline Provoking perceptions & The storytelling, the characters, \\
\hline
\end{tabular}




\begin{tabular}{|c|c|}
\hline & the metaphors. \\
\hline Arousing emotions & $\begin{array}{l}\text { The background music, the } \\
\text { narrations, the songs, the } \\
\text { characters' voices. }\end{array}$ \\
\hline Interesting & $\begin{array}{l}\text { The behaviors, the metaphors, } \\
\text { the audio cues. }\end{array}$ \\
\hline Challenge & The storytelling \\
\hline Appealing & $\begin{array}{l}\text { The characters, the storytelling, } \\
\text { the layout. }\end{array}$ \\
\hline Encouraging & $\begin{array}{l}\text { The navigation, the behavior, the } \\
\text { visual cue, the audio cue. }\end{array}$ \\
\hline Entertaining & The storytelling, the behavior. \\
\hline Guiding & $\begin{array}{l}\text { The annotated navigator, the } \\
\text { miniature buttons. }\end{array}$ \\
\hline Engaging & The storytelling, the behavior. \\
\hline Flexible & $\begin{array}{l}\text { The narration enabler, the hybrid } \\
\text { navigator. }\end{array}$ \\
\hline \multicolumn{2}{|c|}{ Fun: data gathered through observing subjects' behavior } \\
\hline Laugh & $\begin{array}{l}\text { All children were found laughing } \\
\text { and smiling at certain parts of } \\
\text { the DST. }\end{array}$ \\
\hline Humor & $\begin{array}{c}\text { The subjects were making jokes } \\
\text { with their friends when } \\
\text { interacting with the DST. }\end{array}$ \\
\hline Relax & $\begin{array}{l}\text { Subjects were found very relax } \\
\text { when interacting with the DST. } \\
\text { They were not stressed although } \\
\text { they have to click buttons for } \\
\text { moving to different pages } \\
\text { because they were in the flow } \\
\text { with the storytelling. }\end{array}$ \\
\hline Happy & $\begin{array}{c}\text { When the subjects were provided } \\
\text { with control over the DST, they } \\
\text { were found happy interacting } \\
\text { with it. }\end{array}$ \\
\hline Fun & $\begin{array}{l}\text { All subjects were found happy } \\
\text { interacting with the DST through } \\
\text { the way they sing together the } \\
\text { narrations, and utilizing the } \\
\text { features in the DST. }\end{array}$ \\
\hline Enjoyable & $\begin{array}{l}\text { When the subjects finished } \\
\text { reading the DST, all of them } \\
\text { were found repeating a few } \\
\text { times, trying the features and } \\
\text { enjoying the behaviors as } \\
\text { outlined in previous section. }\end{array}$ \\
\hline Excited & $\begin{array}{l}\text { Each subject who was in the } \\
\text { state of waiting for their turn to } \\
\text { interact with the DST was found } \\
\text { very excited. They keep pushing } \\
\text { their friend to finish quickly. }\end{array}$ \\
\hline
\end{tabular}

The results in Table 2 were gathered through annotating their comments and behaviors. In detail, most data on entertaining aspects were gathered through annotating their comments trough the think-aloud protocol, while data on fun were gathered by their behaviors. Then, the following section discusses the obtained data.

\section{DISCUSSION}

Generally, all data were gathered in the subjects' natural environment as they preferred. Their peers were allowed to accompany them, with a hypothesis that they will communicate with their peers when interacting with the DST. This study regards their communications as valuable data; especially this study focuses on user experience in terms of entertaining and fun.

From Table 1, it can be seen that all criteria for entertaining are well-supported in the DST. Subjects found all criteria in different features, in which each criterion is supported by multiple features. The storytelling itself is very important in making the DST entertaining. This means, if the storytelling is weak, it negatively affects the DST. Besides, annotated navigator, characters, audio and visual cue, and other interactive elements are important in supports of being entertaining. These elements ensure that the readers are in the state of knowing their status, and their actions.

In addition, the criteria of fun were obviously observable. All subjects were enjoying their experience interacting with the DST. All of them asked to interact with the DST repetitively. The results as presented in Table 1 indicate that the DST are entertaining and invoking fun. The features in the DST which include use of various media elements, non-complex navigation, minimum user efforts, supports of recognition through metaphor, clear user feedback through direct manipulation, and multiple choices on user actions supports for the positive user experience specifically the entertaining and fun.

DST is a reading material which is easily developed by anyone. [46] discusses the potentials of DST including experience sharing. So, it is a usable technology especially in learning. Teachers could develop personal DST for their children, or encourage their students to design their DST for sharing with the friends as part of learning activities.

\section{CONCLUSION}

Overall, this study found that the DST is entertaining reading material that is able to invoke fun among the readers, especially the children. Entertaining and fun are different in meaning in which entertaining refers to anything that engage people; whether it is horror, comedy, drama, sport, war, or sad. In contrast, fun is something associate with laugh, happiness, and excitement. They are both semantics of user experience. However, Incorporation of design principles in the DST is important in supports of the user experience. This study argues that if the DST is designed without complying with any design principle, users will experience the DST differently. Hence, another study is possible to compare results of DST with and without complying design principles.

In this study, the data were gathered through observation to understand the context at initial level. It could be strengthened with empirical data so that the evidence is more accurate. So, empirical data collection shall be carried out next. 


\section{ACKNOWLEDGMENTS}

A special thanks to University of Science and Technology Sana'a Yemen and Universiti Teknologi MARA for giving full cooperation towards the completion of this paper. All the guidelines and resources are very beneficial to the successful of this project. Without cooperation and effort, this paper will not be materialized.

\section{REFERENCES}

[1] Norshuhada, S. \& Landoni, M., "Children's e-book technology: devices, books and book Builder", International Journal of Information Technology in Childhood Education Annual, 2003.

[2] Carvajal, D. 1999. Racing to convert books to bytes. The New York Times. (Dec. 1999).

[3] Preece, J., Rogers, Y., and Sharp, H. 2007 Interaction Design: Beyond Human-Computer Interaction. John Wiley and Sons, Ltd.

[4] Cooper, A., Reinmann, R., and Cronin, D. 2007 About Face 3: The Essentials of Interaction Design. Wiley Publishing Inc.

[5] Sobihatun-Nur, A. S., Asmidah, A. and Ariffin, A. M. 2006. Comparing different types of e-book reader. In Proceedings of International Conference of Computing and Informatics.

[6] Landoni, M. 1997 The Visual Book System: A Study of the Use of Visual Rhetoric in the Design of Electronic Books. Doctoral Thesis. University of Strathclyde.

[7] Norshuhada, S., Landoni, M., Gibb, F. and Shahizan, H., "E-books technology and its potential applications in distance education", Journal of Digital Information, 2003, in British Computer Society and Oxford University Press.

[8] Baloian, N., Berges, A., Buschmann, S., Gaßner, K., Hardings, J., Hoppe, H.U. and Luther, W. 2002. Documant management in a computer integrated classroom. In Proceedings of CRIWG and $8^{\text {th }}$ International Workshop on Groupware.

[9] Malone, T.W. 1980. What makes things fun to learn? heuristics for designing instructional computer games. In Proceedings of the Joint Symposium of $3{ }^{\text {rd }}$ SIGSMALL and $1^{\text {st }}$ SIGPC Symposium on Small System.

[10] Wiberg, C. 2005. Usability and fun: an overview of the relevant research in the HCI community. In Proceedings of the CHI Workshop on Innovative Approaches to Evaluating Affective Interfaces.

[11] Kaye, J.J. 2007. Evaluating experience-focused HCI. In Proceedings of CHI 2007.

[12] Wolf, M.J. 1999 The Entertainment Economy. Penguin Books.

[13] Ariffin, A.M. and Norshuhada, S. 2009. Entertaining and fun: experience-focused e-learning material. In Proceedings of the International Conference on Computing and Informatics.
[14] Barnum, C.M. 2002 Usability Testing and Research. Pearson Education, Inc.

[15] Carroll, J.M. and Thomas, J.C. 1988. Fun in SIGCHI Bulletin.

[16] Wickens, C. D., Gordon, S. E., and Liu, Y. 1998 An Introduction to Human Factors Engineering. AddisonWesley Educational Publishers Inc.

[17] Kwon, H.S. and Chidambaram, L. 2000. A test of the technology acceptance model: the case of cellular telephone adoption. In Proceedings of the $33^{\text {rd }}$ Hawaii International Conference on System Sciences.

[18] Dix, A., Finlay, J., Abowd, G. D., and Beale, R. 2004 Human-computer Interaction. Pearson Education Ltd.

[19] Evans, E.A. 1993. A modular design for user satisfaction assessment. In Proceedings of $21^{\text {st }}$ ACM SIGUCCS.

[20] Harrison, A.W. and Rainer Jr, R.K. 1996. A general measure of user computing satisfaction in Computers in Human Behavior.

[21] Mahmood, M.A., Burn, J.M., Gemoets, L.A. and Jacquez, C., "Variables affecting information technology end-user satisfaction: a meta-analysis of the empirical literature" International Journal of Human-Computer Studies, 2000.

[22] Chin, W.W. and Lee, M.K.O. 2000. A proposed and measurement instrument for the formation of IS satisfaction: the case of end-user computing satisfaction. In Proceedings of International Conference on Information Systems.

[23] Lindgaard, G. and Dudek, C. 2003. What is this evasive beast we call satisfaction? Interacting with Computers.

[24] Berry, D. 2000. The User Experience: The Iceberg Analogy of Usability. Retrieved August 19, 2007 from http://www.ibm.com/developerworks/web/library/wberry $/$ dwzone $=$ web

[25] Wright, P., McCarthy, J. \& Marsh, T. 2000. From Usability to User Experience. A British HCI Group One-Day Meeting on: Computers and Fun 3. Retrieved August 19, 2007 from http://wwwusers.york.ac.uk/ am1/C\&F3abs.PDF

[26] Monk, A., Hassenzahl, M, Blyth, M., and Reed, D. 2002. Funology: designing enjoyment. In Proceedings of CHI.

[27] Lera, E.D. and Garreta-Domingo, M. 2007. Ten emotion heuristics: guidelines for assessing the user's affective dimension easily and cost-effectively. In Proceedings of the $21^{\text {st }}$ BCS HCI Group Conference.

[28] Malone, T.W. 1981 What makes computer games fun in Byte.

[29] Malone, T.W. 1984. Heuristics for designing enjoyable user interfaces: lessons from computer games. In Thomas, J.C. and Schneider, M.L. (Eds), Human Factors in Computer Systems. Ablex Publishing Corp.

[30] Amory, A., Naicker, K., Vincent, J., and Adams, C., "The use of computer games as an educational tool: identification of appropriate game types and game 
elements", British Journal of Educational Technology, 1999.

[31] Pinhanez, C., Karat, C., Vergo, J., Karat, J., Arora, R., Riecken, D., and Cofino, T. 2001. Can the web be passive? In Proceedings of International WWW.

[32] Karat, C., Pinhanez, C., Karat, J., Arora, R., \& Vergo, J. 2001. Less clicking, more watching: results of the iterative design and evaluation of entertaining web experiences. In Proceedings of Interact' 2001.

[33] Asgari, M., and Kaufman, D. 2004. Relationships among computer games, fantasy and learning. In Proceedings of Educating Imaginative Minds, 2nd Annual Conference on Imagination and Education.

[34] Neal, L., Miller, D., and Perez, R. 2004. Online learning and fun. eLearn Megazine.(Sept 2004).

[35] MacFarlane, S., Sim, G., and Horton, M. 2005. Assessing usability and fun in educational software. In Proceedings of the 2005 Conference on Interaction Design and Children.

[36] Malone, T.W. and Lepper, M.R. 1987 Making learning fun: a taxonomy of intrinsic motivations for learning in Snow, R.E \& Farr M.J. (Eds.) Aptitude, Learning, and Instruction. Lawrance Erlbaum.

[37] Sanders, M. and Ayayee, E. 1997. Engaging learners in computer aided learning: putting the horse before cart. In the Proceedings of ASCILITE 97.

[38] Perry, T.L. 2001. Evaluating Multimedia. Retrieved December 13, 2007 from http://productivity.com/evalmm.htm
[39] Carroll, J.M. 2004. Beyond fun in Interactions.

[40] Pikkarainen, T., Pikkarainen, K., Karjaluoto, H. and Pahnila, S. 2004. Consumer acceptance of online banking: an extension of the technology acceptance model in Internet Research

[41] Mandryk, R.L., Inkpen, K.M. and Calvert, T.W., "Using psychophysiological techniques to measure user experience with entertainment technologies", Journal of Behaviour and Information Technology, 2006.

[42] Chesney, T., "An acceptance model for useful and fun information systems". An Interdisciplinary Journal on Human in ICT Environments, 2006.

[43] Garzotto, F. 2008. Broadening children's involvement as design partners: from technology to experience. In Proceedings of $7^{\text {th }}$ International Conference of Interaction Design and Children.

[44] Nielsen, J., Clemmensen, T. and Yssing, C. 2002. Getting access to what goes on in people's head?: reflections on the think-aloud technique. In Proceedings of the 2nd Nordic Conference on Human-Computer Interaction.

[45] Ariffin, A.M., Mohd-Helmy, A.W. and Norshuhada, S. Measures for Entertaining and Fun-Of-Use. MASAUM Journal of Survey and Reviews, 2009.

[46] Ariffin, A.M., Digital Storytelling: An Easy-to-create Usable Information Conveyor. Journal of Information Technology Review, 2010. 